\title{
Investigation on Laser Beam Weldability of AISI 304L Plates Based on Thermal Field Simulation by Experimentally-Fitted Analytical Modeling
}

\author{
Fabio Giudice $^{1}$ (D) Andrea Sili ${ }^{2}$ D
}

Accepted: 22 September 2021 / Published online: 20 October 2021

(C) The Author(s) 2021

\begin{abstract}
The objective of the work is to present a new approach to the simulation of the thermal field in laser beam welding, based on an experimentally-fitted analytical model, applied to investigate the weldability of AISI 304L austenitic steel. Reference is made to the welding trial in a single pass of two $10 \mathrm{~mm}$ thick butt-positioned plates. Welding was performed under the keyhole full penetration mode, which is characteristic of high-power laser beam, and simulated by an analytical model based on a multipoint-line thermal source system and fitted on the experimental fusion zone profile. The model was applied to simulate the effects of welding speed changes on thermal fields and cooling rates, in order to determine how they can affect the weld composition, the solidification mode and the possible formation of a sensitized zone in the heat affected zone. A limit value of welding speed, which allows the weld formation without lack of fusion, was identified. For all the welding speeds considered, the formation of a sensitized zone can be excluded. The contribution of welding speed on cooling rate, not significant near the welding axis, results to be determinant at the boundary of the fused zone with base metal. The combined choice of the filler material and the welding speed, which in all cases gives rise to primary ferrite solidification modes, affects the content of residual ferrite, which must be balanced to enhance the resistance to solidification cracking, avoiding the adverse effects due to too high contents. As a conclusion, the model proves to be a valid support in investigating the thermal effects, which result from the setup of welding parameters, on the weldability of the base metal-filler system.
\end{abstract}

Keywords Laser beam welding - Analytical modeling · Cooling rate · Weldability · AISI 304L steel

Fabio Giudice

fabio.giudice@unict.it

Extended author information available on the last page of the article 


\section{Introduction}

Components of machines and structures made of AISI 304L steel are commonly assembled by welding and it is well-known that weldability issues might occur. In particular the solidification mode of an austenitic steel is crucial to establishing its material susceptibility to hot cracking, considering also other issues, such as sensitizing to intergranular corrosion and loss of toughness, due to carbide precipitation at grain boundaries [1].

Laser beam welding continues to play an increasing role in manufacturing process. Generally, weld quality and efficiency depend on laser beam characteristics, material properties and processing parameters. Metallic materials are considered weldable with a certain process and for given purposes when the integrity of the welded parts and every technical requirement are ensured. Due to the low energy input applied per unit length, laser beam welding allows to weld in a single pass thick plates, producing a narrow heat affected zone (HAZ) and reduced thermal distortions.

With this regard, AISI 304 stainless steel is characterized by a good weldability, being such as to allow full penetration in laser beam welding of plates thick $10 \mathrm{~mm}$ and more, also without filler material [2].

Weldability can also be defined through the metallurgical features of the weld metal and heat affected zones [3]. In fact, austenitic steels undergo the so-called sensitization phenomenon for heating at temperatures around $500{ }^{\circ} \mathrm{C}$. It consists of a chromium carbides precipitation along the grain boundaries, which leaves chromium depleted areas, with the consequent implications in terms of material embrittlement and sensitizing to intergranular corrosion and stress corrosion cracking [4].

The tendency toward hot cracking during weld solidification is another serious issue of weldability for austenitic stainless steels, caused by the presence of little amounts of sulfur and phosphorus; these elements have a strong tendency to segregate along the boundaries of the dendrite grains, forming low-melting point eutectics distributed as a liquid film, resulting in cracks formation under the force of contraction [5]. The presence of a small amount of ferrite enhances the resistance to solidification cracking: if an austenitic steel solidifies primarily as ferrite- $\delta$ with austenite solidification at the latter stage (FA mode), it results less susceptible to hot cracking, due to the high solubility of the impurities in the ferritic phase and the consequent restriction of their partitioning in the interdendritic regions. The $\delta / \gamma$ interface shows also a better cracking resistance than $\delta / \delta$ or $\gamma / \gamma$ ones, because they have higher grain boundary wettability with respect to the eutectic liquid enriched by impurities, as discussed in [6] and more recently in [7] where the role of the microstructure of the mushy zone is experimentally highlighted.

The ability to predict microstructures and properties of austenitic stainless steels, according to the heating during welding and the subsequent cooling phase, is the topic of many researches. Recently, several studies have been developed to simulate, by the finite element method (FEM), the welding thermal fields (for a review on these numerical methods, see the work of Marques et al. [8]). Furthermore, Sun et al. [9] carried out a work to evaluate the dilution grade in multi pass arc welding 
and predict the final microstructure of the weld; more recently, Kik [10] calibrated the heat source by selecting the finite element mesh in such a way that the calculated shape of the melt pool corresponds to that from real tests. However, these numerical simulations require increasing computing capacity and time, according to the degree of accuracy of the mesh into which the joint is subdivided [11], and needs to be validated by experimental measurements which, by their nature, are specific of the welding conditions considered [12].

A less complex approach, from the point of view of the thermal field calculation, is given by the phenomenological laws of the heat conduction (for a review on this approach to thermal field modeling, see the work carried out by Mackwood and Crafer [13]; a complete overview on basic mathematical formulation of the heat sources in conduction-based modeling is reported by Franco et al. [14]). In the case of high-power laser beam welding, however, a model based only on heat conduction would not take into account the complex fluid dynamics phenomena inside the keyhole, which affect the thermal distribution and are very difficult to simulate analytically. So, in order to compensate for the simplification inherent in the modelling carried out according to the laws of heat conduction, an experimentally-fitted multipoint-line system of the thermal source was proposed by Giudice et al. [15]. The parameters of the source system were set in order to obtain the best fit between the analytical profile of the fused zone (FZ) and the one detected experimentally, with the purpose of giving a complete $3 \mathrm{D}$ simulation of the resulting thermal field.

With the core objective to demonstrate the usefulness of the model in investigating the laser beam weldability of a base metal-filler system, in a previous work [16] it was applied to evaluate thermal field and cooling rates in laser beam welded AISI $304 \mathrm{~L}$ steel plates. The simulation carried out allowed to foresee the weld composition, solidification mode, and microstructure (austenite matrix with residual ferrite), resulting in agreement with the experimental observations. This work can be considered as a preliminary approach to a full-field investigation of the AISI 304 steel weldability, and did not take into account the effects of variations in the main process parameters.

Particularly, welding speed can have important effects on material weldability, as investigated in literature by simplified analytical models of the thermal condition over time applied to high strength steel [17], or by numerical simulation (FEM) aimed at assessing the effects on mechanical properties of duplex stainless steel welds [18].

In the present work, referring to the case of butt-welded AISI 304L thick plates, the potential of the proposed analytical approach to heat source modeling has been investigated, with specific regard to the prediction of the effects on thermal field and cooling rates, due to welding speed variations, and their consequences on the metallurgical properties of welding. In particular, the cooling rate has turned out to be a crucible parameter to determine the fused zone microstructure. As a matter of fact, based on results in the literature, not only the weld composition, but the two parameters together determine the percentage of residual ferrite, or ferrite number $(\mathrm{FN})$, resulting decisive for the weld performance $[19,20]$. For example, for AISI 304 steel the optimum value of FN is in the range $4-8 \%$. At low cooling rates, this value depends primarily on the weld 
composition. In this respect a good value of the ratio $\mathrm{Cr}_{\mathrm{eq}} / \mathrm{Ni}_{\mathrm{eq}}$ is around 1.7 , but the consequence of high cooling rates, which can be reached during laser beam welding, are not to be overlooked: cooling rates higher than $10^{2} \mathrm{~K} / \mathrm{s}$ lead to the formation of an excessive amount of residual ferrite, which is detrimental to the mechanical properties [20].

With these premises, the current work presents a novel and more complete investigation of the AISI $304 \mathrm{~L}$ laser beam weldability, focused on the following fundamental parameters, which in turn depend on the welding speed:

- the composition of the fused zone FZ, considering both the use of filler material (which becomes necessary in the case of very thick plates or welding of dissimilar steels), and the case of autogenous welding;

- the cooling rate at the interface between FZ and the base metal, where the melt pool solidification starts, and the sensitivity to the formation of solidification cracks is high.

Furthermore, it has to be considered that the cooling rate governs both the solidification process and the subsequent solid-state transformations, so as to determine the final microstructural characteristics of this specific region. Therefore, its trend at the FZ boundary has been analyzed along the whole cooling paths corresponding to different values of $\mathrm{v}$, from the liquidus to the solidus temperatures, for a check of the solidification mode, and down to the lower limit of the miscibility gap $(\delta+\gamma)$, to predict the percentage of residual ferrite, which is due to the solid-state transformation $\delta \rightarrow \gamma$.

\section{Materials and methods}

\section{Welding trial}

Two plates (each one with length 1000, width $1000 \mathrm{~mm}$ and thickness $10 \mathrm{~mm}$ ), made of austenitic steel AISI 304L, were butt-welded in a single-pass by a $\mathrm{CO}_{2}$ gas laser beam.

Although AISI 304 steel can be welded in an autogenous way, the plates were prepared with square edges, no gap, and filler material interposed in the form of four consumable inserts (each one being a sheet with length 1000, height $10 \mathrm{~mm}$ and width $0.4 \mathrm{~mm}$ ), in order to diversify the FZ composition. The inserts were initially fixed by gas tungsten arc tack-welding. The gap absence avoids energy losses due to the laser beam reflections on the metal internal surface, which were investigated in [21].

The incident beam energy is so high that the portion of irradiated material melts and vaporizes, forming a capillary cavity (keyhole), surrounded by molten metal. At high temperatures, a part of the vapor ionizes forming plasma, which is harmful because it absorbs energy and attenuates the laser beam effects. The control of plasma was performed by a transverse helium flow, through a nozzle, directed above the interaction zone of the laser beam with the molten bath. Helium is technically preferable to argon, although more expensive, because of its greater resistance to 
ionization. The experimental setup, developed for clad steel in [22], is shown in Fig. 1; the process parameters are given in Table 1.

The focus position was located beneath the upper surface of the plates at a distance $\Delta z=5.5 \mathrm{~mm}$, which is indicated by a positive number as, for simplicity of calculation, in the model a reference system with the origin on the plate upper surface and the z-axis oriented downwards has been considered.

The compositions of base (BM) and filler material (FM) are shown in Table 2. $\mathrm{BM}$ consists of two plates of AISI 304L. The letter L indicates a reduced carbon concentration respect to the usual concentration $\mathrm{C}=0.08 \%$ of the common AISI 304 grades, with the purpose of limiting the risk of carbide precipitation.

The inserts utilized for the welding trial were made of AWS 309L, more alloyed than AISI 304 steel and thus suitable for welding dissimilar materials. This filler material was chosen to diversify the composition of the FZ with respect to that of the BM, and compare the contents of $\mathrm{Ni}$ and $\mathrm{Cr}$ detected experimentally in the joint with those obtained by applying the analytical model.

Furthermore, simulations were carried out hypothesizing that the consumable inserts are made of AWS 308L, which is a less alloyed filler material commonly used for welding AISI 304L [23].

For a useful comparison, the case of autogenous welding was also considered in the simulations.

This specific welding procedure was chosen because, in addition to being easy to use, it ensures great tolerance with respect to any geometric imperfections in the preparation of the edges and/or errors in the alignment of the beam; moreover, with a correct number of inserts, it allows the avoidance of the risk of incomplete fusion more easily than using filler wire. By this way, it is also possible to obtain an easier control of the degree of dilution.

Visual inspections, performed for a first quality check, ascertained that the welded bead is free from cracks and other macroscopic defects. Macrographic observations of the cross-section showed a full penetration of the fused zone (FZ) along the whole plates thickness: it has a regular shape, with a width of about $2 \mathrm{~mm}$, which becomes slightly wider near the external surface at the laser beam side and shows a certain
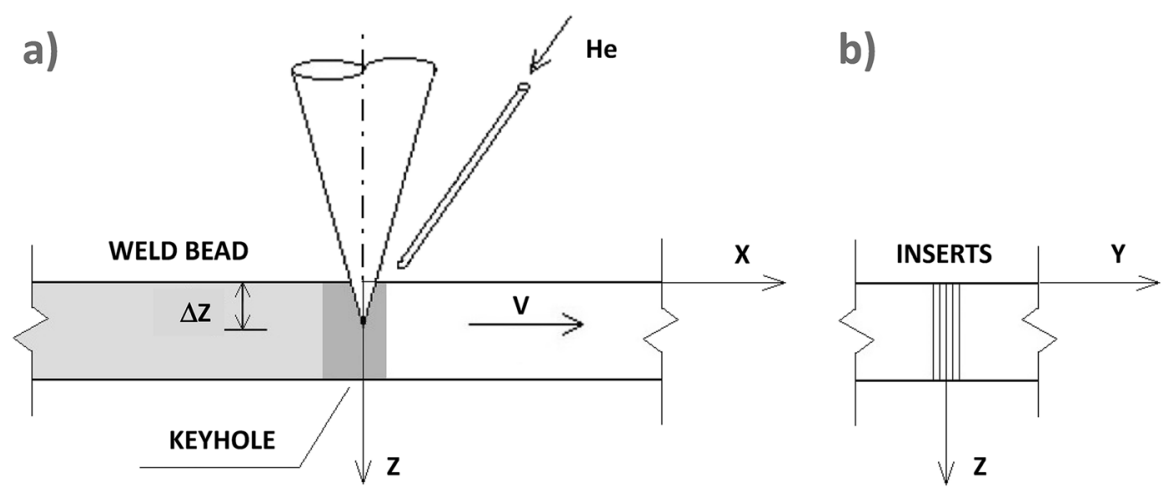

Fig. 1 Setup of the welding process: a cross-section, b longitudinal section of the plates 
Table 1 Laser beam welding parameters

\begin{tabular}{llllll}
\hline $\begin{array}{l}\text { Laser beam } \\
\text { power } \mathrm{P}(\mathrm{kW})\end{array}$ & $\begin{array}{l}\text { Welding speed } \\
\mathrm{v}(\mathrm{m} / \mathrm{min})\end{array}$ & $\begin{array}{l}\text { Focus } \\
\text { diameter } \\
(\mathrm{mm})\end{array}$ & $\begin{array}{l}\text { Focus } \\
\text { position } \Delta \mathrm{z} \\
(\mathrm{mm})\end{array}$ & $\begin{array}{l}\text { Helium flow } \\
\text { rate }(\mathrm{l} / \mathrm{min})\end{array}$ & Consumable inserts $(\mathrm{mm})$ \\
\hline 14 & 1.2 & 0.5 & 5.5 & 20 & $1.6(4$ sheets, each width $0.4 \mathrm{~mm})$ \\
\hline
\end{tabular}

enlargement in correspondence to the focus position (Fig. 2a). The micrographs, taken after a suitable metallographic preparation by mechanical grinding and etching through the Glyceregia reagent $\left(16 \% \mathrm{HNO}_{3}, 42 \% \mathrm{HCl}, 42 \%\right.$ glycerol), show a regular boundary of the FZ and no enlargements of the austenitic grains in the BM (Fig. 2b); the FZ has a homogeneous dendritic structure, characterized by austenitic matrix with the presence of residual ferrite (Fig. 2c).

\section{Thermal field modeling}

The actual heat input generated by the keyhole and its effects on the melt pool and on the weld cross-sections was modeled by a heat sources system constituted by a line source along the entire thickness and two point sources located, respectively, on the surface and inside the joint, at the focus point of the laser.

It is well kwon that a line source produces a thermal profile uniform along the plate thickness, while a point source introduces also thermal gradients along the thickness [13]. Hence, it is a fact that both of these sources are far from approximating the actual temperature distribution produced during laser beam welding. Therefore, in our work we experimented a parameterized combination of these types of sources that can simulate the real distribution of temperatures. The parameters of the source system were set in order to obtain the best fit between the analytical profile of the fused zone and the one detected experimentally.

Considering a reference system (x,y,z), whose origin is fixed to the thermal source, that moves along the welding axis $\mathrm{x}$ with speed $\mathrm{v}(\mathrm{m} / \mathrm{s})$, in the case of a point heat source $\mathrm{Q}_{\mathrm{P}}(\mathrm{W})$ the temperature $\mathrm{T}(\mathrm{x}, \mathrm{y}, \mathrm{z})$ in a generic point is given by the following equation:

$$
T(x, y, z)=T_{0}+\frac{Q_{P}}{c \pi k r_{P}} e^{-\frac{v}{2 \alpha}\left(r_{P}+x\right)}
$$

where $T_{0}$ is the initial temperature, $c$ a numeric coefficient, $\mathrm{k}(\mathrm{W} / \mathrm{mK})$ the thermal conductivity, $\alpha\left(\mathrm{m}^{2} / \mathrm{s}\right)$ the diffusivity, $\mathrm{r}_{\mathrm{P}}(\mathrm{m})$ the radial distance from the point source:

$$
r_{P}=\sqrt{x^{2}+y^{2}+\left(z-z_{P}\right)^{2}}
$$

where $z_{\mathrm{P}}$ is the depth of the mobile source respect to the axes' origin, which is located on the body surface. 
Table 2 Composition of the base metal and the filler (\% by weight)

\begin{tabular}{llllllllll}
\hline & $\mathrm{C}$ & $\mathrm{Mn}$ & $\mathrm{Si}$ & $\mathrm{P}$ & $\mathrm{S}$ & $\mathrm{Ni}$ & $\mathrm{Cr}$ & $\mathrm{Mo}$ & $\mathrm{Fe}$ \\
\hline AISI 304L & 0.018 & 1.15 & 0.41 & 0.025 & 0.001 & 10.1 & 18.4 & - & $\mathrm{Bal}$ \\
AWS 309L & 0.010 & 1.65 & 0.33 & 0.020 & 0.010 & 12.4 & 24.5 & 0.47 & $\mathrm{Bal}$ \\
AWS 308L $^{\mathrm{b}}$ & 0.025 & 1.40 & 0.30 & 0.030 & 0.030 & 10.0 & 20.0 & - & $\mathrm{Bal}$ \\
\hline
\end{tabular}

${ }^{\mathrm{a}} \mathrm{FM}$ utilized for the experimental welding trial and for the analytical simulations.

${ }^{\mathrm{b}} \mathrm{FM}$ also considered for the analytical simulations.

The numeric coefficient in the denominator of Eq. (1) is $c=2$ when $z_{P}=0$ (point source on the body surface) and $c=4$ when $z_{P}>0$ (point source inside the body).

In the case of a mobile source uniformly distributed on a line along the body thickness ( $\mathrm{z}$ axis), Rosenthal [24] gives the following equation for the temperature fields in the plane xy:

$$
T(x, y)=T_{0}+\frac{Q_{L}}{2 \pi k} e^{-\frac{v}{2 \alpha} x} K_{0}\left(\frac{v r_{L}}{2 \alpha}\right)
$$

where $\mathrm{Q}_{\mathrm{L}}(\mathrm{W} / \mathrm{m})$ is the power per unit of the source length, $\mathrm{K}_{0}$ the modified Bessel function of the second kind of order zero, $r_{L}(m)$ the radial distance from the source in the plane xy:

$$
r_{L}=\sqrt{x^{2}+y^{2}}
$$

The approach presented in [15] is based on the set up the system of types (1) and (3) sources, able to produce the same thermal effect of the actual interaction between the laser beam and the workpiece, without evaluating the complex energytransfer processes that characterize keyhole mode laser welding. This effect is represented by the shape and boundaries of the weld bead on the plane orthogonal to the direction of source movement. The generalized model can be adapted to the specific case to be analyzed, on the basis of the geometrical features of the experimentally detected bead cross-section.

By varying the configuration of the model, it is possible to simulate the thermal sources system capable of determining the laser welding beads of the most common shapes, from those typical of deep penetration laser welding, to those characterized by low penetration and parabolic cross-section beads. After the setup of the most suitable combination of heat sources, the multi-source model is defined in detail by fitting, on the shape of the bead cross-section experimentally detected, the parameters that characterize the geometric layout and strength of the sources: the length of the line source and the location depth of the point sources $\left(z_{L}, z_{P 1}, \ldots, z_{P i}, \ldots\right)$, which define the layout of the model; the distribution coefficients $\left(\gamma_{\mathrm{L}}, \gamma_{\mathrm{P} 1}, \ldots, \gamma_{\mathrm{Pi}}\right.$, ...) of the laser's thermal power absorbed by the keyhole, which define the strength distribution among the sources.

In the case under consideration, the thermal analysis was carried out by an analytic model based on the superimposition of two point sources and one line source, 


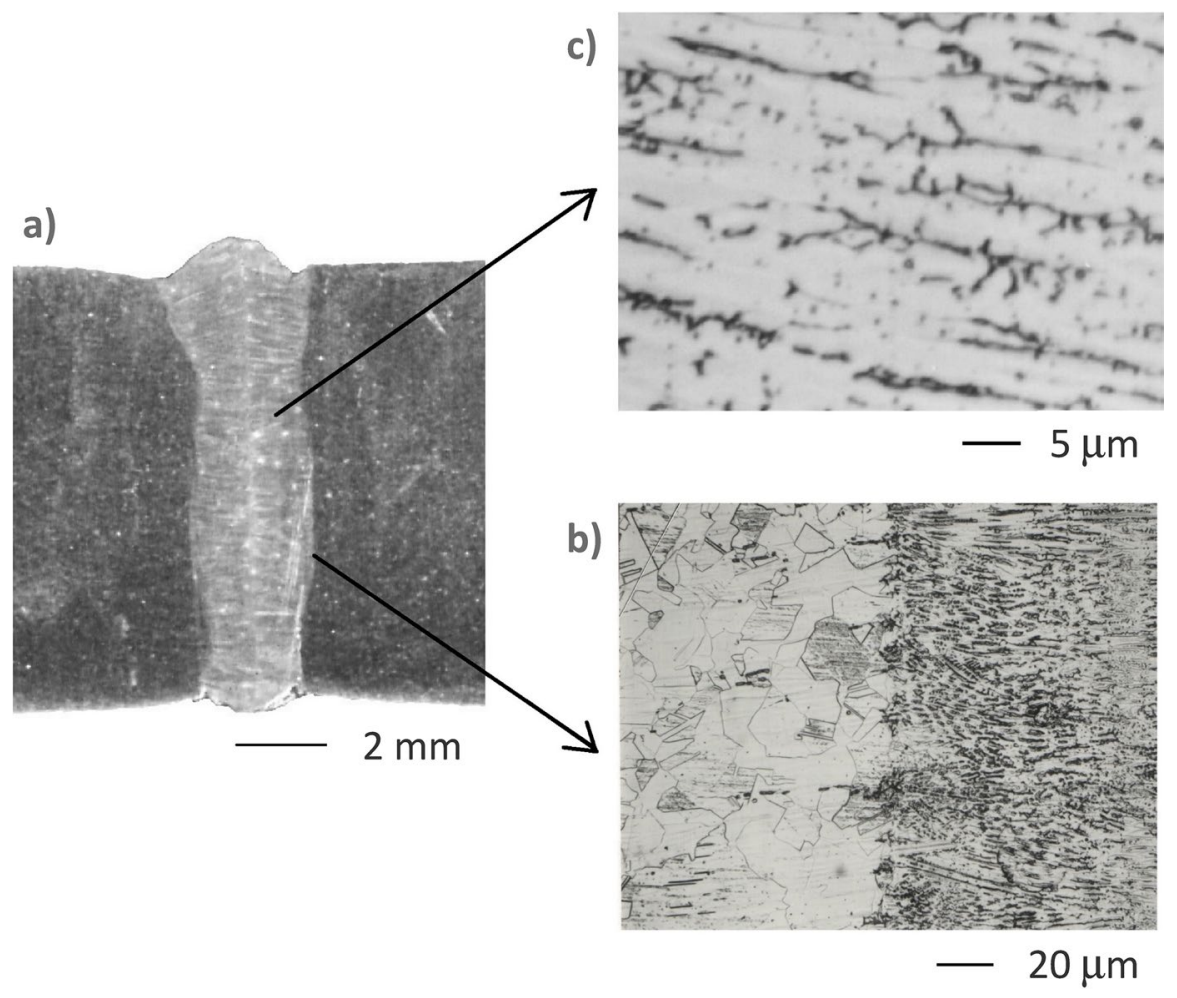

Fig. 2 Macro- and micrographic images taken on the welded section: a welded bead cross-section, b FZ boundary, $\mathbf{c}$ FZ microstructure

whose thermal fields, according to the conductivity-based modeling previously introduced, are expressed by Eqs. (1) and (3):

$$
T(x, y, z)=T_{0}+\sum_{i=1}^{2} \frac{Q_{P i}}{c_{i} \pi k r_{P i}} e^{-\frac{v}{2 \alpha}\left(r_{P i}+x\right)}+\frac{Q_{L}}{2 \pi k} e^{-\frac{v}{2 \alpha} x} K_{0}\left(\frac{v r_{L}}{2 \alpha}\right)
$$

where $T_{0}$ is assumed equal to the room temperature $(293 \mathrm{~K})$.

To simulate the full penetration welding and the keyhole effect, reproducing the experimental profile of the molten area in the best possible way, the thermal sources were located as follows:

- first point source on the external surface, at the laser beam side $\left(\mathrm{z}_{\mathrm{P} 1}=0 \mathrm{~mm}\right)$;

- second point source inside the bead where the beam is focused $\left(\mathrm{z}_{\mathrm{P} 2}=\Delta \mathrm{z}=5.5 \mathrm{~mm}\right)$;

- line source along the whole bead thickness $\left(\mathrm{z}_{\mathrm{L}}=10 \mathrm{~mm}\right)$.

This choice was made according to the morphology of the FZ profile in the welded section: the line source contributes to the formation of a regular shape of the FZ along the entire thickness, while the point sources give rise to the convexities 
that characterize the experimental profile, respectively, near the surface exposed to the laser beam and inside the joint, where the beam is focused.

Once the model layout was defined, the sources' strength parameters $\gamma_{\mathrm{L}}$ and $\gamma_{\mathrm{Pi}}$ were introduced in order to distribute the overall power of the laser beam between the line and the two point sources. Of course, the sum of these partition coefficients of the thermal power must respect the condition: $\gamma_{\mathrm{L}}+\gamma_{\mathrm{P} 1}+\gamma_{\mathrm{P} 2}=1$.

Being $\mathrm{P}=14 \mathrm{~kW}$, the net power carried by the laser beam, the fraction absorbed by the plates can be expressed by introducing the coefficient $\eta<1$, in order to exclude the fraction absorbed by the plasma and dispersed in the environment. Therefore, the following expressions of the power delivered by each source are defined by the following expressions:

$$
Q_{P i}=\gamma_{P i} \eta P \quad Q_{L}=\gamma_{L} \eta P / z_{L}
$$

under the condition of balancing the total power input:

$$
\eta P=\sum_{i=1}^{2} Q_{P i}+Q_{L} z_{L}
$$

The absorption coefficient $\eta$ in Eqs. (6) and (7), and the sources' strength distribution parameters $\gamma_{\mathrm{Pi}}$ and $\gamma_{\mathrm{L}}$, are variables to be determined numerically to allow the best fitting of the analytical profile on the experimental FZ boundaries.

Assuming, in all the considered cases, constant values at $\mathrm{T}=700{ }^{\circ} \mathrm{C}$ (Table 3) for the thermophysical parameters, the construction of a 3D model of the FZ was achieved by applying Eq. (5) in order to obtain the isothermal curves on horizontal planes at different values of $\mathrm{z}$.

Equation (5) allows the expression of the thermal field of the two point and line sources model in each point $(\mathrm{x}, \mathrm{y}, \mathrm{z})$ according to the reference system fixed on the heat source moving on the surface of the workpiece. To analyze the temperature cycles in a fixed detection point, as time varies, i.e., as the distance of the mobile sources from the detection point varies during their movement, the following coordinate transformation must be operated in Eq. (5):

$$
x \rightarrow \xi=x-v t
$$

where $\mathrm{v}$ is the moving speed along the $\mathrm{x}$ axis, and $\mathrm{t}$ is the time.

By means of this transformation, a fixed point on the workpiece, with respect to the mobile reference system xyz, is identified by the coordinates $(\xi, y, z)$.

The model is further implemented to determine the cooling rate in $(\xi, \mathrm{y}, \mathrm{z})$ fixed points of the workpiece, deriving Eq. (5) with respect to time after having transformed $\mathrm{x}$ into $\xi(8)$ :

$$
\frac{\partial T(\xi, y, z)}{\partial t}=\sum_{i=1}^{2}\left[\frac{a_{i}^{\prime} v \xi e^{-b\left(r_{P_{i}}+\xi\right)}}{r_{P i}^{3}}-\frac{a_{i}^{\prime} b\left(-\frac{v \xi}{r_{P_{i}}}-v\right) e^{-b\left(r_{P i}+\xi\right)}}{r_{P i}}\right]+\left[a^{\prime \prime} b v e^{-b \xi} K_{0}\left(b r_{L}\right)+\frac{a^{\prime \prime} b v \xi e^{-b \xi} K_{1}\left(b r_{L}\right)}{r_{L}}\right]
$$

being $\mathrm{a}^{\prime}{ }_{\mathrm{i}}=\mathrm{Q}_{\mathrm{Pi}} / \mathrm{c}_{\mathrm{i}} \pi \mathrm{k}, \mathrm{a}^{\prime}{ }^{\prime}=\mathrm{Q}_{\mathrm{L}} / 2 \pi \mathrm{k}, \mathrm{b}=\mathrm{v} / 2 \alpha, \mathrm{r}_{\mathrm{Pi}}$ and $\mathrm{r}_{\mathrm{L}}$ expressed by Eqs. (2) and (4) where the transformation $\mathrm{x} \rightarrow \xi$ is applied, $\mathrm{K}_{0}$ and $\mathrm{K}_{1}$ are the modified Bessel function of the second kind of order zero and one. This equation allows the calculation 
Table 3 Thermophysical parameters utilized in the calculation [25]

\begin{tabular}{llll}
\hline $\begin{array}{l}\text { Solidus temp Ts } \\
(\mathrm{K})\end{array}$ & Density $\rho\left(\mathrm{kg} / \mathrm{m}^{3}\right)$ & $\begin{array}{l}\text { Specific heat } \mathrm{C}_{\mathrm{p}}(\mathrm{J} / \\
\mathrm{kg} \mathrm{K})\end{array}$ & $\begin{array}{l}\text { Thermal conduct } \mathrm{k} \\
(\mathrm{W} / \mathrm{m} \mathrm{K})\end{array}$
\end{tabular}

of the cooling rates at each point $(\xi, \mathrm{y}, \mathrm{z})$, as the heat sources approach it and move away along the $\mathrm{x}$ direction.

\section{Application and preliminary results}

\section{Experimental fitting of theoretical model}

Figure 3 shows the 3D modeling of the melt pool together with the fitting of theoretical FZ profile on the one detected experimentally in the cross-section plane of the welded joint. The isothermal surface of the melt pool (at $1400{ }^{\circ} \mathrm{C}$ solidus temperature) was constructed by calculating the isothermal curves on xy planes at various depths along the $\mathrm{z}$ axis (Fig. 3a). The theoretical profile of the weld bead was calculated by projecting the maximum contour of the $3 \mathrm{D}$ model of the melt pool onto the yz plane (Fig. 3b). In this way, the imprint of the maximum width of the FZ on the cross-section of the joint was obtained.

The fitting with the experimental profile was optimized by minimizing the sum of the squared distances along the y axis, between the experimental and the theoretically calculated profiles (Fig. 3c). The optimization was performed by the evolutionary solving tool implemented in Excel, obtaining the convergence to a stable solution that closely approximates the experimental profile.

As a result of this procedure, the distribution parameters of the beam power $\left(\gamma_{\mathrm{L}}=0.81\right.$, $\left.\gamma_{P 1}=0.10, \gamma_{P 2}=0.09\right)$ and the absorption coefficient $(\eta=0.51)$ were obtained. With regard to the latter result, a model presented to calculate the absorption terms in keyhole mode laser welding [26] has been applied to the specific conditions under consideration, allowing to estimate $\eta=0.55$, a value that validates the fitting of the calculated profile to the experimental one. This value is aligned with those calculated in [27].

\section{Simulations of welding thermal behavior}

Once the model has been fitted, various simulations to evaluate the effects of the mobile heating source can be performed. With the purpose of evaluating the effects of the welding speed $\mathrm{v}$, four different values $(0.4,0.9,1.5$ and $1.8 \mathrm{~m} /$ $\min )$ have been considered in addition to the experimental value ( $\mathrm{v}=1.2 \mathrm{~m} / \mathrm{min}$ ). Figure $4 \mathrm{a}$ shows the FZ profiles in the transverse plane zy calculated for each welding speed. The corresponding weld seams, constructed for each speed $\mathrm{v}$, are shown in Fig. $4 \mathrm{~b}$. 


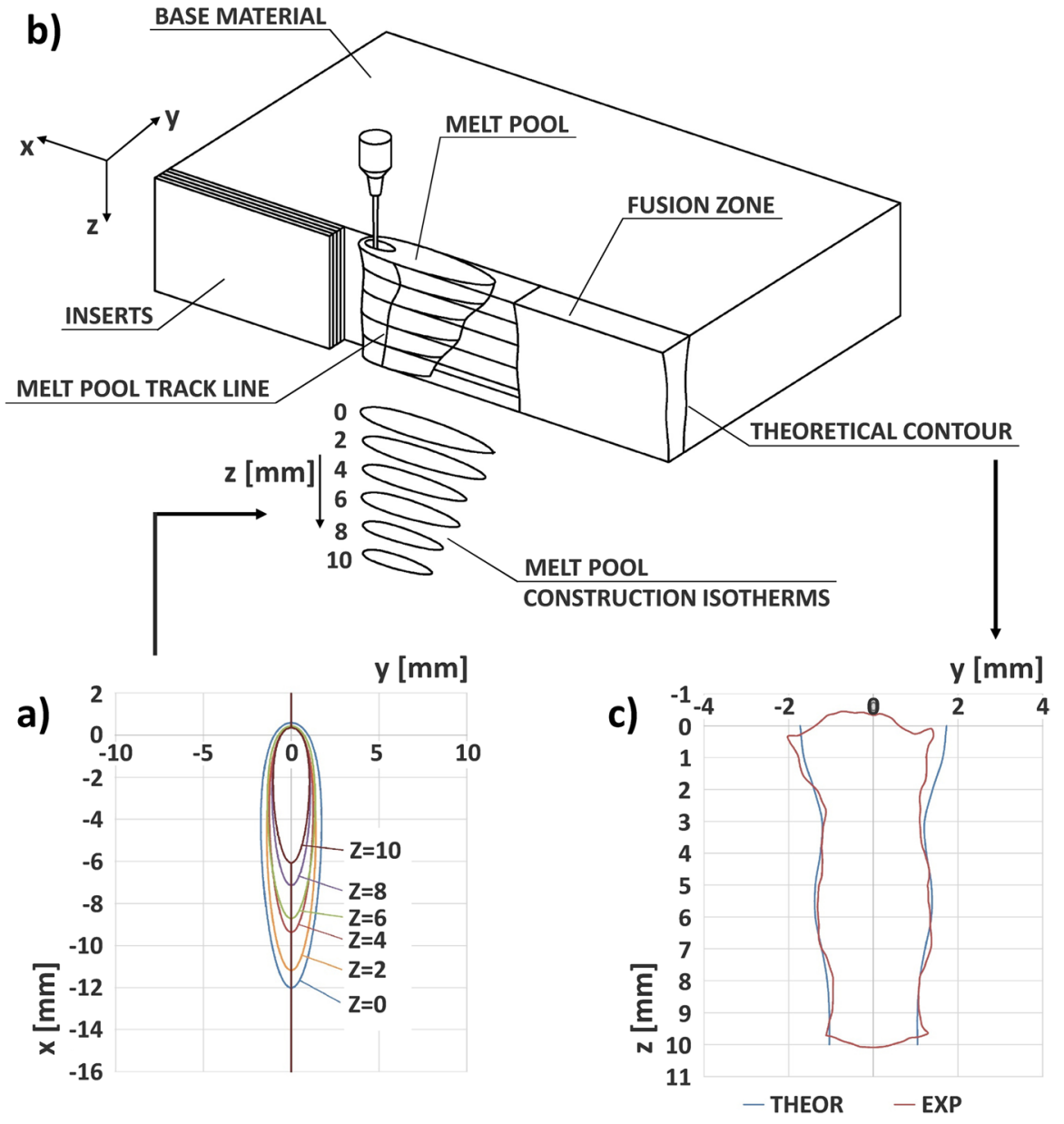

Fig. 3 FZ modeling: a isothermal curves for melt pool construction, b 3D model of the melt pool and projection of the FZ cross-section profile, c comparison between the calculated and experimental profiles of the weld bead cross-section

Focusing on the FZ cross-sections represented by the profiles in Fig. 4a, in which the area occupied by the inserts is represented by the gray rectangles, it can be observed that the thermal input is generally sufficient for their complete fusion together with a part of the base material. The condition corresponding to the highest speed $(\mathrm{v}=1.8 \mathrm{~m} / \mathrm{min})$ is an exception: in this case the extension of the molten area, in correspondence to some regions along the thickness, is not fully sufficient and reveal the possibility of weld defects onset, due to incomplete fusion of the filler metal.

In Fig. 4c, for each of the intermediate simulated welding speed $(0.9,1.2$, $1.5 \mathrm{~m} / \mathrm{min}$ ), the isotherms in the plane $\mathrm{xy}$ at $\mathrm{z}=5 \mathrm{~mm}$ (i.e. at the center of the plate thickness) are drawn for three significant temperatures: $1400{ }^{\circ} \mathrm{C}$ solidus temperature, $500{ }^{\circ} \mathrm{C}$ lower limit and $850{ }^{\circ} \mathrm{C}$ upper limit of temperature for carbide 
b)

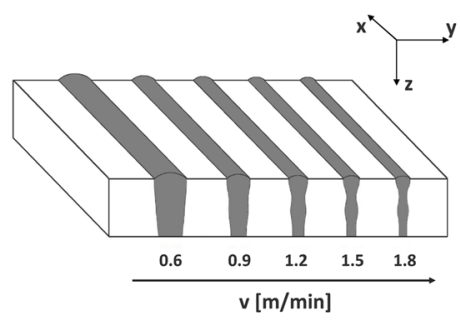

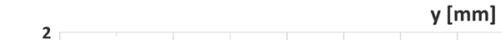

d)

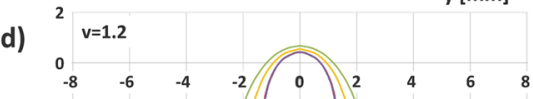

a) ${ }^{-1}-4 \quad \mathrm{y}[\mathrm{mm}]$

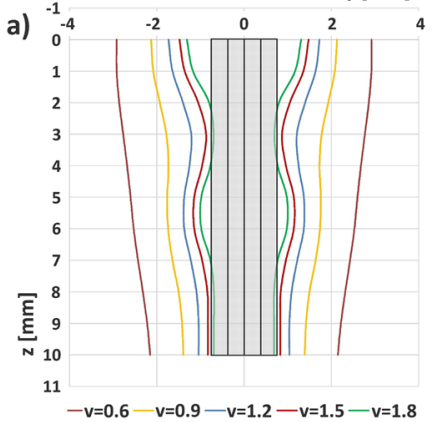

c)

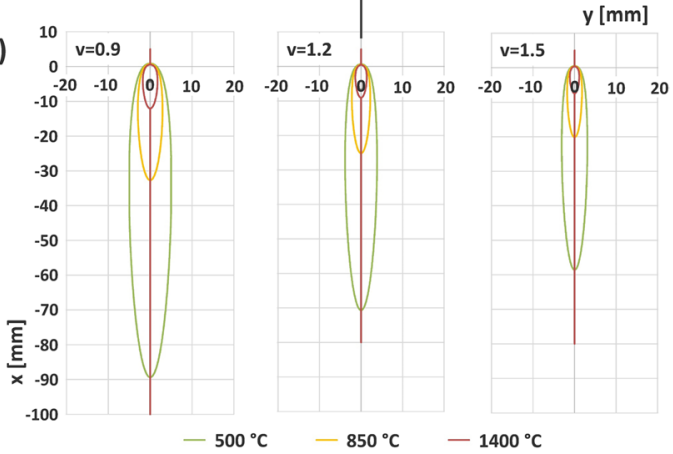

Fig. 4 Simulation results: a profiles of the FZ as the welding speed v varies, $\mathbf{b}$ weld seams construction, $\mathbf{c}$ isotherms in the $x y$ plane at $\mathrm{z}=5 \mathrm{~mm}$ corresponding to the intermediate values of $\mathrm{v}$ considered, d detail of the FZ boundary for $\mathrm{v}=1.2 \mathrm{~m} / \mathrm{min}$, with the two limit isotherms at liquidus and solidus temperatures

precipitation. These isotherms give an indication of the width of the FZ and the zone heated in the sensitizing range of temperature.

Finally, Fig. 4d shows in detail the FZ boundary for $\mathrm{v}=1.2 \mathrm{~m} / \mathrm{min}$, highlighting two limit isotherms at liquidus $\left(1454{ }^{\circ} \mathrm{C}\right)$ and solidus $\left(1400{ }^{\circ} \mathrm{C}\right)$ temperatures, respectively. This detail anticipates the way the FZ boundary has been modeled for the simulation of the whole cooling path, which has to comprise both the solidification stage (from liquidus to solidus temperatures), and the subsequent solid-state cooling stage down to solvus temperature. With this purpose, the FZ boundary will be considered as a region between two limits, defined by the points such that the maximum of the thermal cycle is equal to the liquidus and the solidus temperature, respectively.

The temperature-time curves, obtained by means of the $\mathrm{x} \rightarrow \xi$ transformation (8), are shown in Fig. 5 for $\mathrm{v}=0.6 \mathrm{~m} / \mathrm{min}$ (lower welding speed, to which corresponds the greatest heat input), at different distances y from the welding axis, being $\mathrm{y}=2.60 \mathrm{~mm}$ the value corresponding to the FZ-HAZ limit.

The intersections of these curves with the horizontal dashed lines allow the calculation of the permanence time in the sensitizing range $500-850{ }^{\circ} \mathrm{C}$. In the case under 


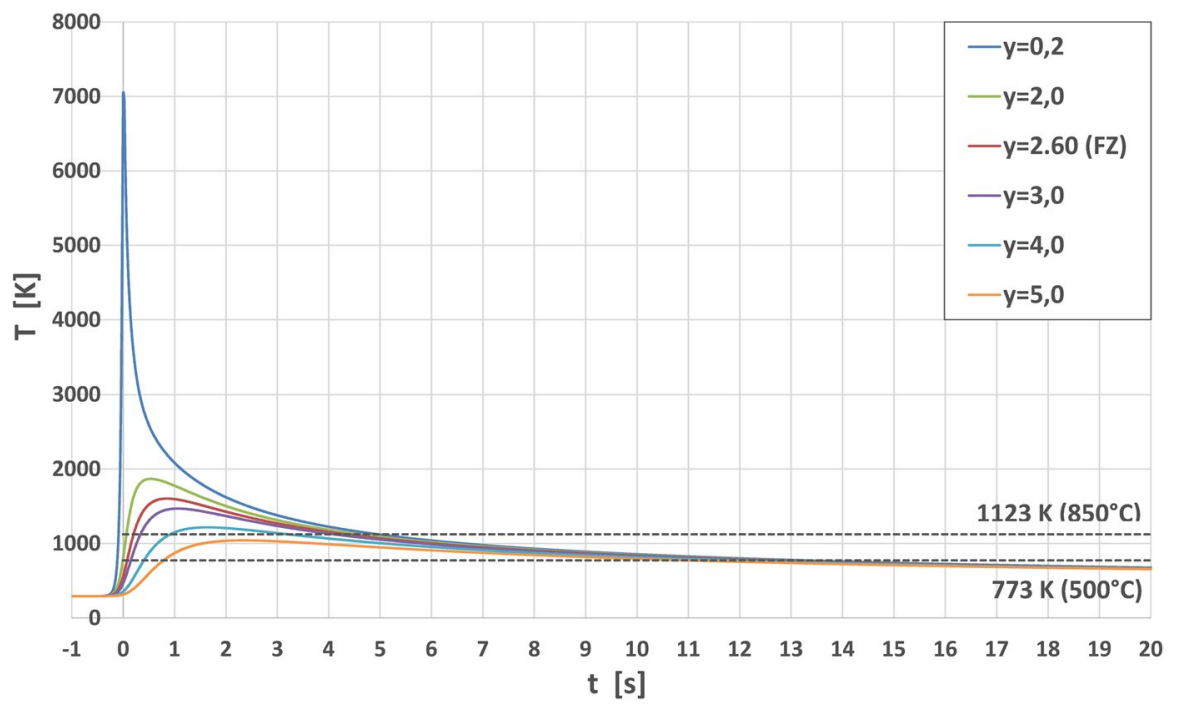

Fig. 5 Temperature-time trends for the indicated values of $y$, at $z=5 \mathrm{~mm}$ and $v=0.6 \mathrm{~m} / \mathrm{min}$

examination, due to the short permanence time, which reach a maximum value equal to about $12 \mathrm{~s}$ for $\mathrm{v}=0.6 \mathrm{~m} / \mathrm{min}$, this kind of deterioration can be excluded [28].

The cooling rate were calculated through the Eq. (9) for the welding speeds considered, near the welding axis at $y=0.2 \mathrm{~mm}$ and in correspondence of the FZ boundary. Values of y lower than $0.2 \mathrm{~mm}$, i.e. a greater proximity to the welding axis were not considered because the Rosenthal-type equations lose reliability, being based on the incident point source hypothesis that leads to infinite temperature at the sources $(y=0)$ [24].

Results of the Eq. (9) application on the plane $x y$, at $z=5 \mathrm{~mm}$, are shown in Figs. 6 and 7. It can be observed that at $y=0.2 \mathrm{~mm}$ (Fig. 6), the cooling rates are very high, reaching maximum values around $6 \cdot 10^{4} \mathrm{~K} / \mathrm{s}$, which are very similar for the five welding speeds analyzed.

With regards to the FZ boundary, as anticipated before and shown by Fig. 4d, it has been modeled as a region between an internal and external limit, defined by the points at the distance $y$ from the welding axis such that the maximum of the thermal cycle is equal to the liquidus temperature $\left(1454{ }^{\circ} \mathrm{C}\right)$ and the solidus temperature $\left(1400{ }^{\circ} \mathrm{C}\right)$, respectively. Within these two limits, during heating, the base metal only partially melts; in particular, the external limit defines the welding contour beyond which the base metal remains in the solid state, and therefore is the boundary between the FZ and the HAZ. The internal limit of the FZ boundary, instead, defines the distance from the welding axis where the cooling starts exactly from the liquidus temperature, and thus includes the whole solidification down to the solidus temperature, and the subsequent solid-state transformation down to the solvus temperature, during which the structural constituents are created in the specific quantities which will characterize the FZ boundary region at room temperature. 


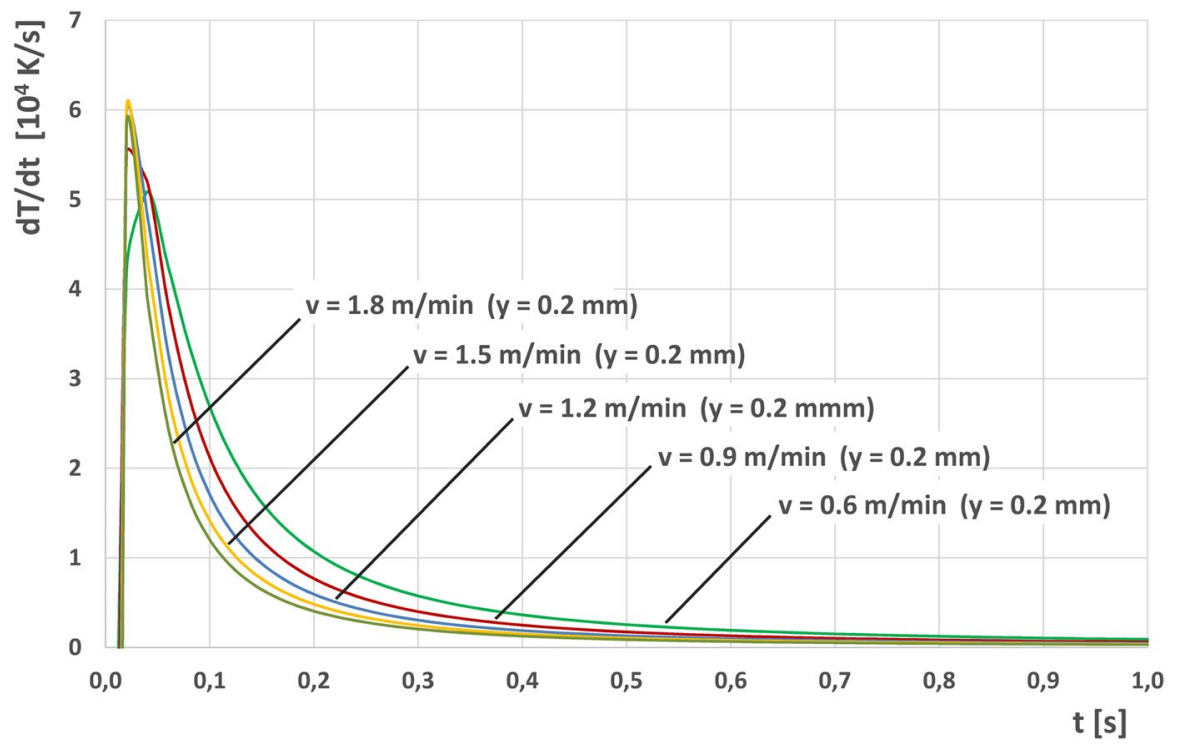

Fig. 6 Cooling rate curves for the five welding speeds considered, at $z=5 \mathrm{~mm}$ and $\mathrm{y}=0.2 \mathrm{~mm}$

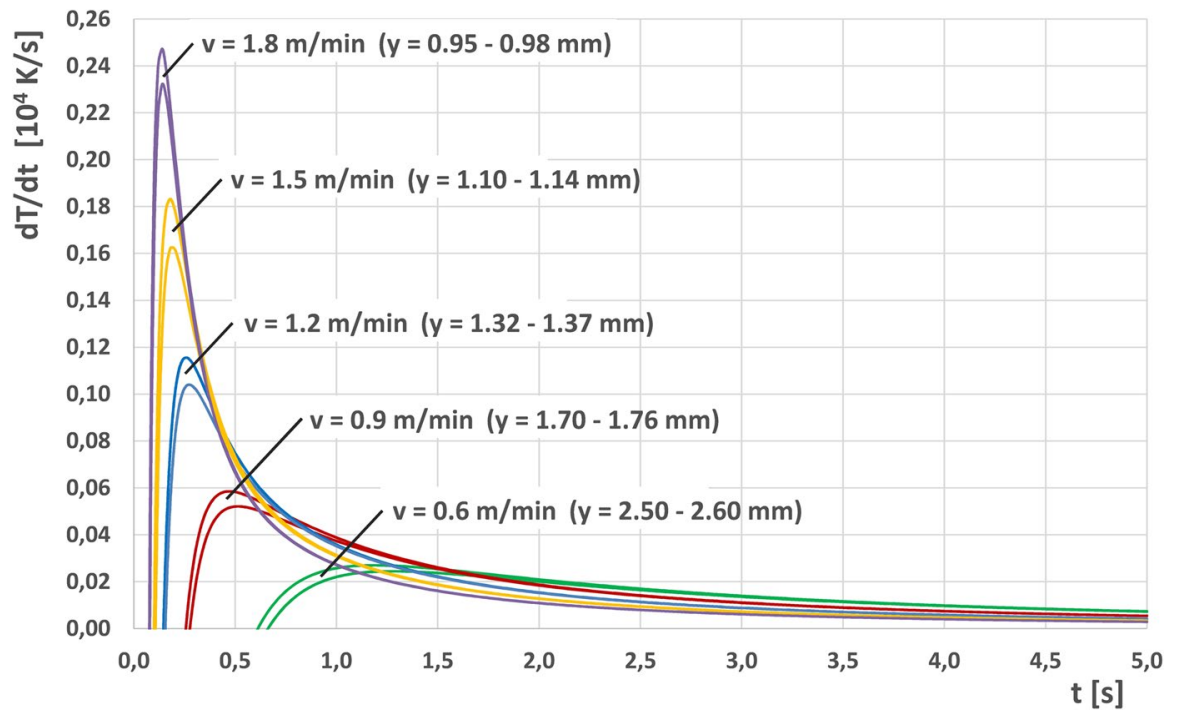

Fig. 7 Cooling rate curves for the five welding speeds considered, at $\mathrm{z}=5 \mathrm{~mm}$ and at the FZ internal and external boundary limits

As a consequence, the cooling rates at the FZ boundaries (Fig. 7) are differentiated between these two limit points, for each welding speed. In this case the maximum values of cooling rates result lower and more varied than those calculated at $\mathrm{y}=0.2 \mathrm{~mm}$. Table 4 reports the detailed maximum values calculated for cooling 
rates at $\mathrm{y}=0.2 \mathrm{~mm}$ and at the internal and external limits of the FZ boundary (with the specification of the corresponding y values, which vary with the welding speed).

As a general conclusion, cooling rates are very high near the welding axis with limited variation as a function of the welding speed. They drastically reduce moving from the welding axis towards the boundary of the fused zone, where the formation of solidification crack is more probable; moreover, in this zone they show significant variations when the welding speed increases.

\section{Extended investigation and discussion}

\section{Fused zone composition and properties}

The filler material composition and the degree of dilution are decisive for the joint properties. Considering the area occupied in the cross-section by the consumable inserts $\left(\mathrm{A}_{\mathrm{FM}}=16 \mathrm{~mm}^{2}\right)$ and the calculated area of the $\mathrm{FZ}\left(\mathrm{A}_{\mathrm{FZ}}\right)$, the weld bead composition can be obtained by carrying out a weighted average of the BM and FM compositions, using as weights $1-\mathrm{A}_{\mathrm{FM}} / \mathrm{A}_{\mathrm{FZ}}$ and $\mathrm{A}_{\mathrm{FM}} / \mathrm{A}_{\mathrm{FZ}}$, respectively.

Obviously, the size of the FZ area is determined by the thermal input and thus by the welding speed, in this case equal to $0.3,0.9,1.2$ (experimental value), 1.5 and $1.8 \mathrm{~m} / \mathrm{min}$. As already observed, the heat input due to $1.5 \mathrm{~m} / \mathrm{min}$ welding speed is just sufficient to avoid a lack of fusion at the interface with the consumable insert (Fig. 4a). So $v=1.5 \mathrm{~m} / \mathrm{min}$ represents a limit value. With this regard, the highest speed $(1.8 \mathrm{~m} /$ min) turns out to be critical. In all cases, excessive welding speeds are not recommended because provides fast cooling rate, resulting into fine dendritic microstructure which enhances the probability of solidification cracking and lack of penetration [29].

The values of $\mathrm{A}_{\mathrm{FZ}}$ and $\mathrm{A}_{\mathrm{FM}} / \mathrm{A}_{\mathrm{FZ}}$, obtained for each welding speed, are given in Table 5. The equivalent value of the weld width (W) was calculated dividing $A_{F Z}$ by the weld depth $(\mathrm{D}=10 \mathrm{~mm})$, in order to obtain the weld depth to width ratio $(\mathrm{R}=\mathrm{D} / \mathrm{W})$, shown in Table 5 . The ratio $\mathrm{R}$ is strongly dependent on the heat input, increasing as $\mathrm{v}$ increases until it approximates the values reported in [2] for fiber laser welding of AISI 304 stainless steel plates without filler material.

The FZ compositions, which depend on the dilution grade and thus on the welding speed, are calculated considering the consumable inserts made of AWS 309L (used in the experimental trial) and also hypothesizing that they are made of AWS 308L. The results are reported in Table 5, together with the equivalent compositions $\mathrm{Ni}_{\mathrm{eq}}=\% \mathrm{Ni}+35 \% \mathrm{C}$ and $\mathrm{Cr}_{\mathrm{eq}}=\% \mathrm{Cr}+\% \mathrm{Mo}$, calculated according to the Welding Research Council diagram (WRC-1992) [30], still widely used today for ferriticaustenitic microstructures.

First of all, it is worth noting that the calculated contents of $\mathrm{Ni}(11.5 \%)$ and $\mathrm{Cr}$ $(22.2 \%)$ for the experimental conditions $(\mathrm{v}=1.2 \mathrm{~m} / \mathrm{min}$ and inserts in AWS 309L) agree with the values measured experimentally by EDS, as reported in [16].

In Table 5 is also given the volume percentage of the residual $\delta$-ferrite, that is the so-called ferrite number (FN), read on the WRC-1992 diagram [30] in correspondence to the calculated values of $\mathrm{N}_{\text {eq }}$ and $\mathrm{Cr}_{\text {eq. }}$. In Fig. 8, the FZ compositions, expressed as $\mathrm{Ni}_{\mathrm{eq}}$ and $\mathrm{Cr}_{\mathrm{eq}}$, are superimposed on the WRC-1992 diagram. 
Table 4 Maximum cooling rates, calculated by Eq. (9) at $\mathrm{y}=0.2 \mathrm{~mm}$ and FZ boundary limits

\begin{tabular}{lllllll}
\hline $\mathrm{v}(\mathrm{m} / \mathrm{min})$ & $\mathrm{y}(\mathrm{mm})$ & $\mathrm{dT} / \mathrm{dt}_{\max }(\mathrm{K} / \mathrm{s})$ & $\begin{array}{l}\text { FZ bound. int. } \\
\text { limit } \mathrm{y}(\mathrm{mm})\end{array}$ & $\mathrm{dT} / \mathrm{dt}_{\max }(\mathrm{K} / \mathrm{s})$ & $\begin{array}{l}\mathrm{FZ} \text { bound. ext. } \\
\text { limit } \mathrm{y}(\mathrm{mm})\end{array}$ & $\mathrm{dT} / \mathrm{dt}_{\max }(\mathrm{K} / \mathrm{s})$ \\
\hline 0.6 & 0.2 & $5.09 \cdot 10^{4}$ & 2.50 & $0.27 \cdot 10^{3}$ & 2.60 & $0.24 \cdot 10^{3}$ \\
0.9 & 0.2 & $5.52 \cdot 10^{4}$ & 1.70 & $0.58 \cdot 10^{3}$ & 1.76 & $0.52 \cdot 10^{3}$ \\
1.2 & 0.2 & $5.94 \cdot 10^{4}$ & 1.32 & $1.16 \cdot 10^{3}$ & 1.37 & $1.04 \cdot 10^{3}$ \\
1.5 & 0.2 & $5.93 \cdot 10^{4}$ & 1.10 & $1.83 \cdot 10^{3}$ & 1.14 & $1.62 \cdot 10^{3}$ \\
1.8 & 0.2 & $5.74 \cdot 10^{4}$ & 0.95 & $2.47 \cdot 10^{3}$ & 0.98 & $2.32 \cdot 10^{3}$ \\
\hline
\end{tabular}

In the case of AWS $309 \mathrm{~L}$ inserts, the weld composition is strongly affected by dilution and thus by the welding speed values; the representative points are characterized by high FN values and solidification as ferrite (F mode), which subsequently transforms partially into austenite during cooling [31]. Conversely, the simulations with the AWS $308 \mathrm{~L}$ inserts gives lower values of FN and representative points placed across the boundary between FA and F mode.

In the case of autogenous welding of AISI $304 \mathrm{~L}$ steel, the solidification mode is FA (in the manner already described in the introduction) with the amount of residual ferrite $\mathrm{FN}=7$ (in the absence of filler material, it is not affected by dilution). This is an optimum value which allows to prevent the hot cracks formation. During cooling of welded structures, the transformation of ferrite into austenite does not proceed to completion and some residual ferrite is retained at room temperature. For example, a content of ferrite up to $10 \%$ is desirable in austenitic welds [28], a condition that can be obtained also in the case of lower speeds (e.i. higher dilutions) by using AWS 308L inserts. Small amount of residual ferrite enhances the resistance to solidification cracking, but the presence of too much ferrite, as that calculated for the inserts in AWS 309L, may give adverse effects, because grains can be selectively attacked by certain corrosive media and ferrite can transform into the brittle $\sigma$ phase at operating temperatures in the range of carbide precipitation.

An alternative approach to the evaluation of FN based on the composition of the FZ has been also applied. It uses a mathematical model to forecast the level of residual $\delta$ ferrite in terms of $\mathrm{FN}$ in austenitic stainless steel welds as a function of $\mathrm{Cr}_{\mathrm{eq}}$ and $\mathrm{Ni}_{\mathrm{eq}}$, and has been proven to provide a more accurate $\mathrm{FN}$ assessment than WRC-1992 within the range of compositions $1.2<\mathrm{Cr}_{\text {eq }} / \mathrm{Ni}_{\text {eq }}<2.0$ and up to $10^{3}{ }^{\circ} \mathrm{C} / \mathrm{s}$ cooling rates [32]. The results, reported in the last column of Table 5, even if underestimate the values of FN, if compared to those derived from the WRC-1992 diagram, confirm the criticality of using AWS 309L inserts in terms of an excessive residual ferrite content.

\section{Analysis of cooling conditions and effects on weldability}

It is a fact that, other than composition, cooling rate is a crucible parameter to determine both the solidification mode and the fused zone microstructure. In laser beam welding, where it is common to encounter cooling rates up to $10^{6} \mathrm{~K} / \mathrm{s}$, rapid 


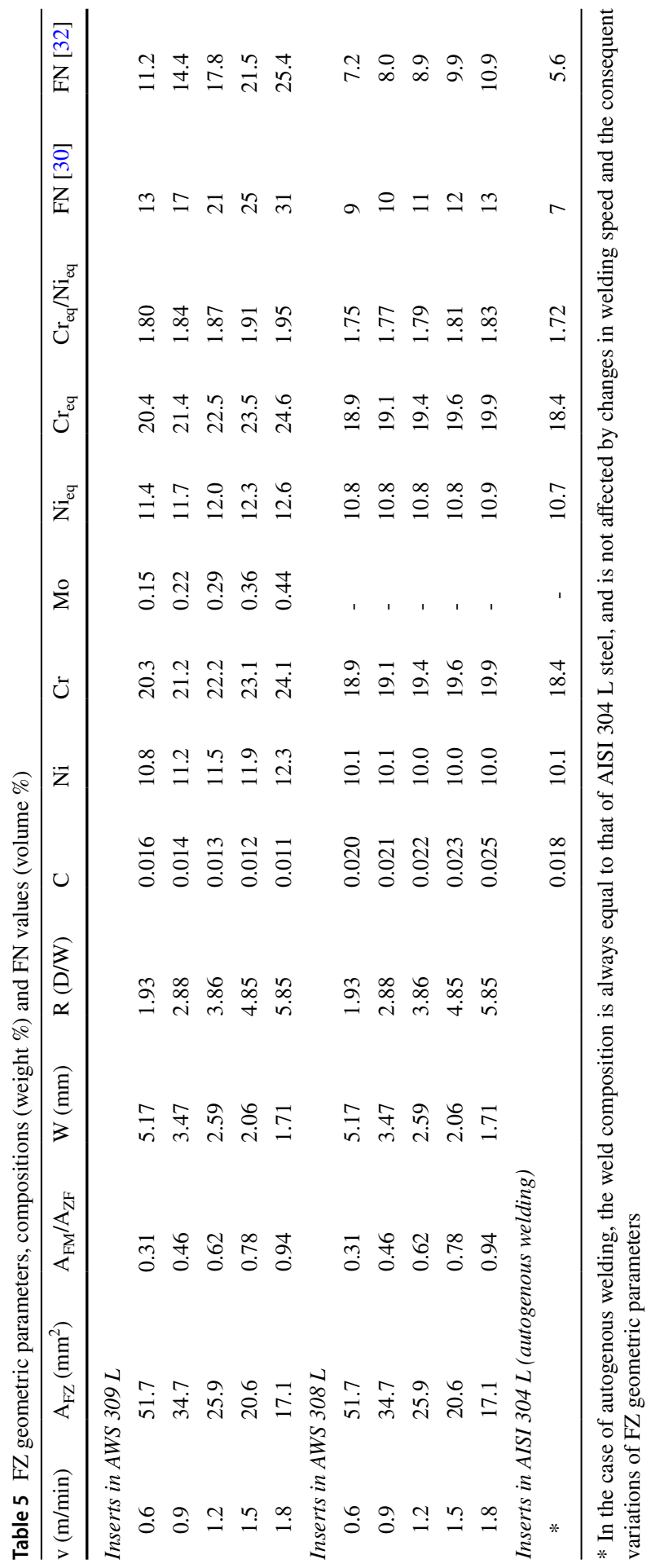




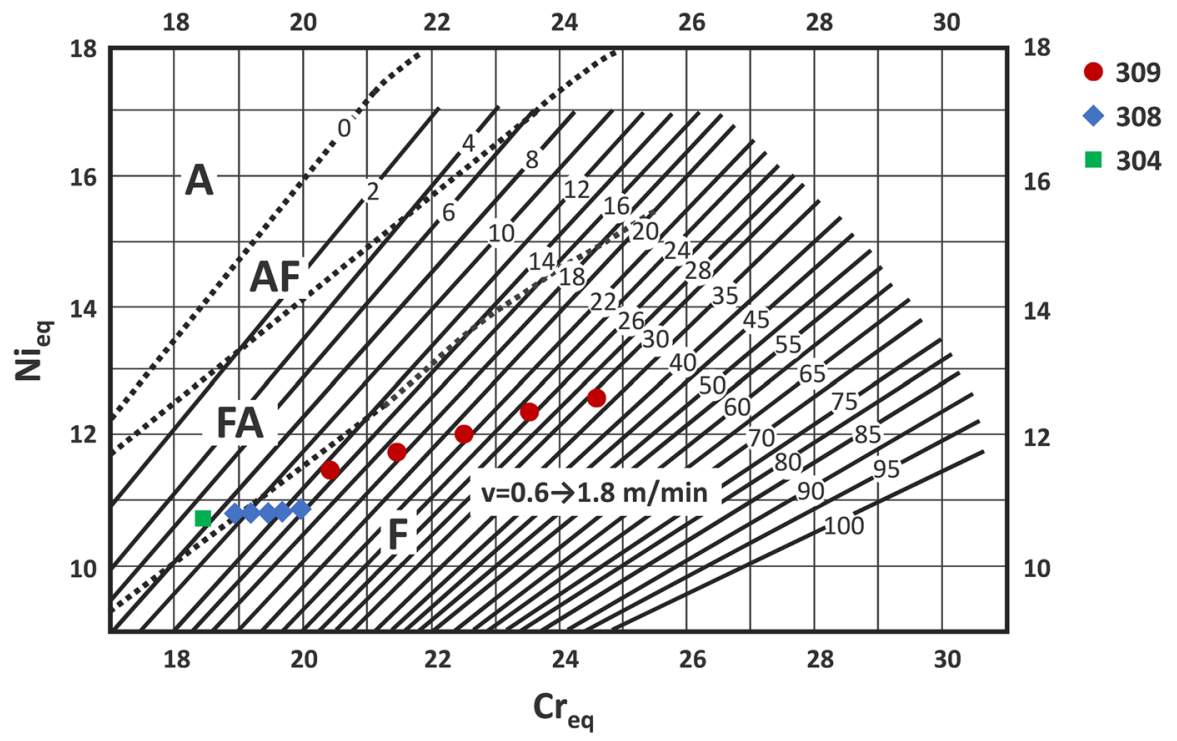

Fig. 8 Representative points of the simulated weld compositions (Table 5), superimposed on the WRC1992 diagram [30]

solidification of materials may produce microstructures during solidification that are markedly different from those observed in more conventional process. In this respect, the work carried out by Vitek et al. [20] deals with a new model, based on a neural network analysis of existing data supplemented with newly generated ones, for predicting ferrite content in stainless steel welds as a function of composition and cooling rate. This model shows, for austenitic stainless steels, an increase in FN with increasing cooling rate, due to the inhibition of the solid-state ferrite to austenite transformation. This trend continues up to a maximum value (equal to $10^{4}$ and $3 \cdot 10^{5} \mathrm{~K} / \mathrm{s}$ respectively for 304 and 309 steels), beyond which it decreases with cooling rate, in accord with the transition to a primary austenitic solidification mode.

On the basis of these findings and considering the previously introduced simulation of cooling rate at the FZ boundary (Fig. 7), where the solidification of the melt pool starts and the formation of solidification cracks is more probable, it is possible to obtain significant predictive information regarding both the solidification mode and the residual ferrite content of the final structure, as the welding speed varies.

Focusing on what in the previous Sect. "Simulations of welding thermal behavior" was defined as the internal limit of the FZ boundary, that is the points at the distance $y$ from the welding axis such that the maximum temperature reached in the thermal cycle is equal to the liquidus temperature, a complete cooling process can be simulated, which includes:

- a first stage of complete solidification starting from the liquidus temperature $(1727 \mathrm{~K})$, under the initial condition of zero cooling rate (the temperature being maximum), and ending at the solidus temperature (1673 K); 


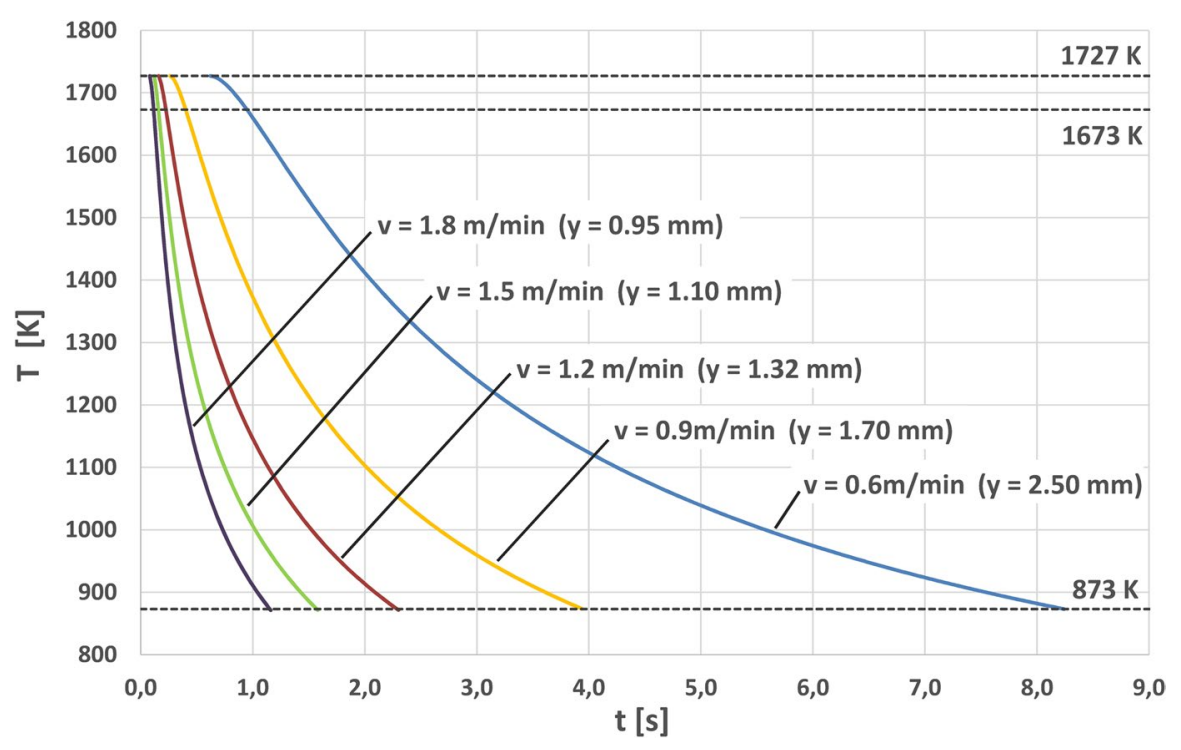

Fig. 9 Cooling path at the FZ boundary $(z=5 \mathrm{~mm})$, as welding speed varies

- a second stage of solid-state transformation down to the solvus temperature (limiting the $\delta+\gamma$ miscibility gap in the $\mathrm{Fe}-\mathrm{Cr}-\mathrm{Ni}$ pseudo-binary system), which for $1.7<\mathrm{Cr}_{\mathrm{eq}} / \mathrm{Ni}_{\mathrm{eq}}<1.8$ can be assumed equal to $600{ }^{\circ} \mathrm{C}(873 \mathrm{~K})$ [33].

Figure 9 shows the cooling paths for each of the considered welding speed, simulated at the points corresponding to the internal limit of the FZ boundary (Table 4). The two stages are defined by the isothermal dashed lines at liquidus, solidus, and solvus temperatures.

Figure 10 shows the cooling rate trends corresponding to the paths in Fig. 9. In each curve, the points corresponding to the liquidus, solidus, and solvus temperatures are highlighted. They divide the cooling rate profiles into the two sections corresponding to the solidification and the subsequent solid-state cooling. Therefore, it is possible to associate to each of the two sections a mean value of the cooling rate, to be taken as a reference for the predictions on the solidification mode and on the microstructural composition at the end of the cooling path, respectively.

The values of the cooling rates at the FZ boundary characterizing the two-stages paths in Fig. 9, calculated as the mean values of the two sections of each cooling rate profile in Fig. 10, are reported in Table 6.

With regards to the first stage (solidification), the limit value of the cooling rate $10^{4} \mathrm{C} / \mathrm{s}$, beyond which primary austenite solidification can occur for both 304 and 309 alloys [20], is not exceeded. Approximately the same limit was considered could be extended in general for $\mathrm{Fe}-\mathrm{Ni}-\mathrm{Cr}$ stainless steels with $\mathrm{Cr}_{\mathrm{eq}}$ l $\mathrm{Ni}_{\text {eq }}>1.60$ [34]. More recent findings have established that this limit condition in laser welding of austenitic stainless steels is lowered to $10^{3}{ }^{\circ} \mathrm{C} / \mathrm{s}$, in the case of alloys characterized by $\mathrm{Cr}_{\mathrm{eq}}+\mathrm{Ni}_{\mathrm{eq}}=35 \%$ and $\mathrm{Cr}_{\mathrm{eq}} / \mathrm{Ni}_{\mathrm{eq}}>1.68$ [35]. It can therefore be concluded that, for each welding speed considered, at all corresponding 


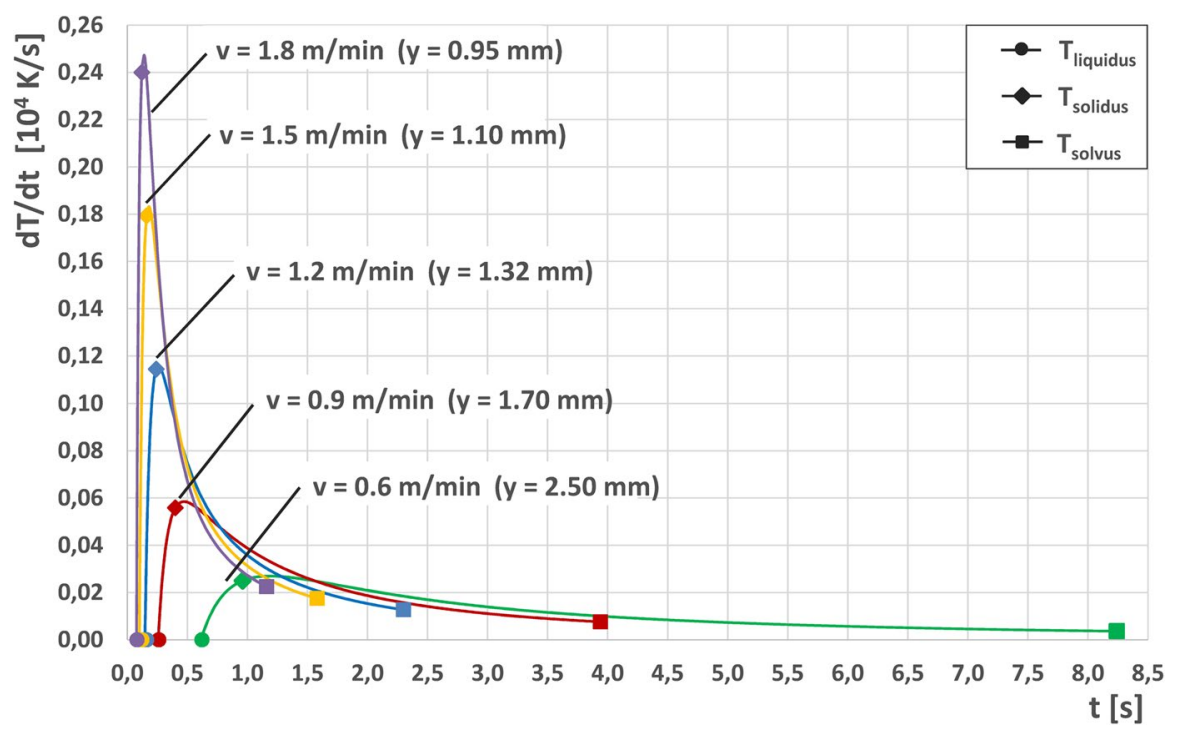

Fig. 10 Cooling rate trends at the FZ boundary $(\mathrm{z}=5 \mathrm{~mm})$ during the two-stages cooling process, as welding speed varies

Table 6 Analysis of the two-stages cooling paths in Fig. 9

\begin{tabular}{|c|c|c|c|c|c|c|}
\hline \multirow[t]{2}{*}{$\mathrm{v}(\mathrm{m} / \mathrm{min})$} & \multirow[t]{2}{*}{$\begin{array}{l}\text { FZ bound. int. } \\
\text { limit y }(\mathrm{mm})\end{array}$} & \multicolumn{2}{|c|}{$\begin{array}{l}\text { Solidification } \\
\mathrm{T}_{\text {liquidus }} \rightarrow \mathrm{T}_{\text {solidus }}\end{array}$} & \multicolumn{3}{|c|}{ Cooling (solid-state) $\mathrm{T}_{\text {solidus }} \rightarrow \mathrm{T}_{\text {solvus }}$} \\
\hline & & $\begin{array}{l}\mathrm{dT} / \mathrm{dt}_{\text {mean }} \\
(\mathrm{K} / \mathrm{s})\end{array}$ & Solid. mode & $\begin{array}{l}\mathrm{dT} / \mathrm{dt}_{\text {mean }} \\
(\mathrm{K} / \mathrm{s})\end{array}$ & $\mathrm{FN}_{\mathrm{CR}} 309$ & $\mathrm{FN}_{\mathrm{CR}} 304$ \\
\hline 0.6 & 2.50 & $0.012 \cdot 10^{3}$ & $\mathrm{FA} / \mathrm{F}$ & $0.015 \cdot 10^{3}$ & 10.0 & 6.0 \\
\hline 0.9 & 1.70 & $0.028 \cdot 10^{3}$ & $\mathrm{FA} / \mathrm{F}$ & $0.033 \cdot 10^{3}$ & 12.0 & 8.5 \\
\hline 1.2 & 1.32 & $0.057 \cdot 10^{3}$ & $\mathrm{FA} / \mathrm{F}$ & $0.064 \cdot 10^{3}$ & 13.5 & 10.5 \\
\hline 1.5 & 1.10 & $0.089 \cdot 10^{3}$ & $\mathrm{FA} / \mathrm{F}$ & $0.100 \cdot 10^{3}$ & 14.5 & 12.0 \\
\hline 1.8 & 0.95 & $0.120 \cdot 10^{3}$ & $\mathrm{FA} / \mathrm{F}$ & $0.135 \cdot 10^{3}$ & 16.0 & 13.0 \\
\hline
\end{tabular}

solidification cooling rates (Table 6) and compositions of the diluted FZ (Table 5), the primary austenitic solidification modes are excluded, confirming the FA or F solidification modes deduced from the WRC-1992 diagram (Fig. 8).

The mean value for cooling rates in the second stage (solid-state transformation inside the $\delta+\gamma$ miscibility gap) is the parameter that affects the residual ferrite content evaluation. Its values calculated according to Vitek et al. [20], as a function of the mean cooling rate $\left(\mathrm{FN}_{\mathrm{CR}}\right)$, are reported in Table 6 for AWS $309 \mathrm{~L}$ filler material and AISI 304 autogenous welding, respectively.

These data are plotted in Fig. 11, showing that for the AWS $309 \mathrm{~L}$ the values of $\mathrm{FN}_{\mathrm{CR}}$ result too high, while for the AISI 304 the welding speed of $1.2 \mathrm{~m} / \mathrm{min}$ represents a watershed below which the values of residual ferrite are acceptable. 


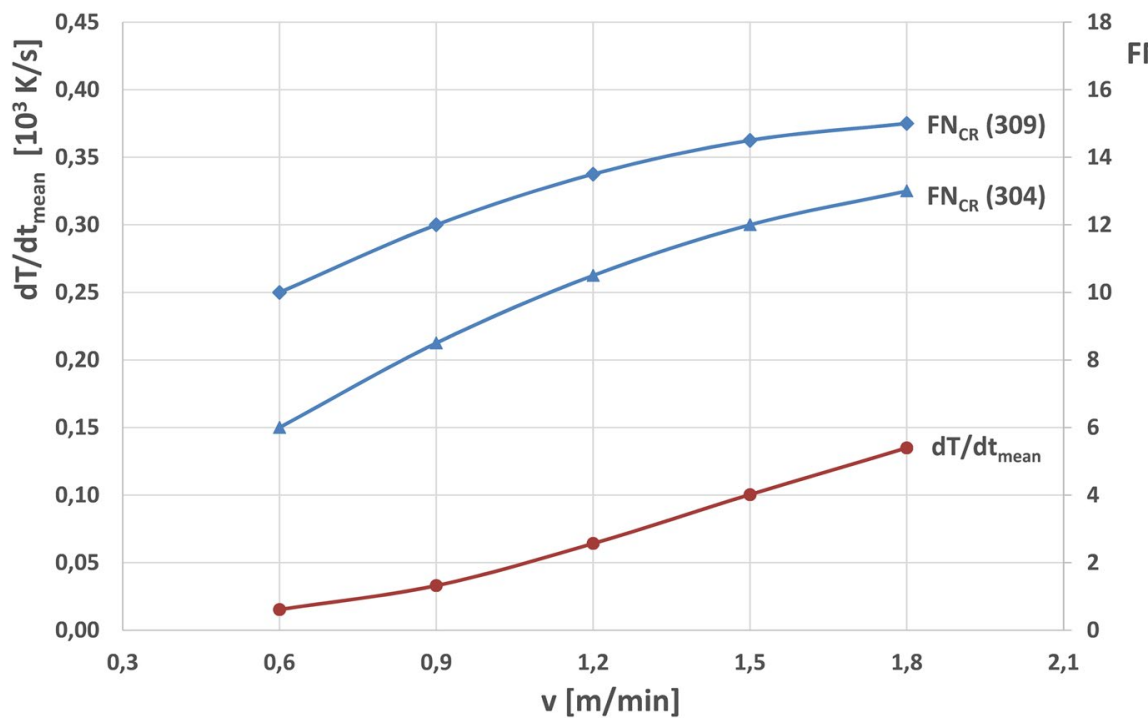

Fig. 11 Mean cooling rate during solid-state transformation at the FZ boundary and corresponding residual ferrite content values $\mathrm{FN}_{\mathrm{CR}}$ vs. welding speed

Finally, in Fig. 12 the trends of $\mathrm{FN}_{\mathrm{CR}}$, calculated as functions of the cooling rate at the FZ boundary corresponding to each welding speed (Table 6, Fig. 11), are compared to the values of the residual ferrite content obtained by means of the compositions of the FZ (Table 5), considering both the WRC-1992 diagram $\left(\mathrm{FN}_{\mathrm{WRC}}\right)$ and the mathematical formulation proposed by Valiente Bermejo [32] $\left(\mathrm{FN}_{\mathrm{VB}}\right)$. These results highlight the determinant effect of the cooling rate in estimating the residual ferrite content in the weld.

\section{Conclusions}

In the present work, an analytical model, based on the assumption of a virtual heat sources system experimentally-fitted on specific process conditions, was used to simulate the thermal field due to high power laser welding. It was applied to investigate the laser beam weldability in a single pass of thick plates, made of AISI 304L austenitic steel, butt-positioned with the interposition of consumable inserts as filler material, with specific regard to the prediction of the effects on thermal field and cooling rates due to welding speed variations, and their consequences on some key metallurgical aspects of welding.

The following conclusions can be drawn:

- A limit value of welding speed, that allows the weld formation without lack of fusion, was identified (it is equal to $1.5 \mathrm{~m} / \mathrm{min}$ in the case considered).

- For all the welding speeds considered, the formation of a sensitized zone can be excluded, due to the short time of permanence between 500 and $850{ }^{\circ} \mathrm{C}$. 


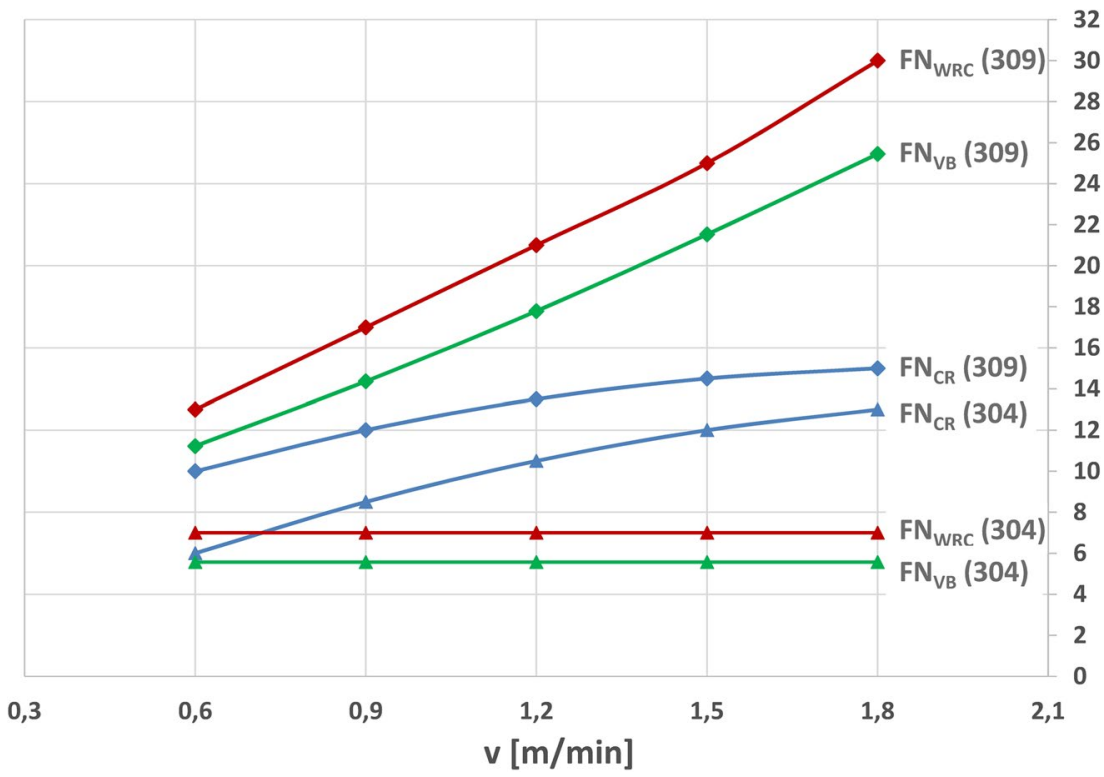

Fig. 12 Comparison between the results of different approaches to the evaluation of residual ferrite content: composition-based approaches $\left(\mathrm{FN}_{\mathrm{WRC}}, \mathrm{FN}_{\mathrm{VB}}\right)$, and cooling rate-based approach $\left(\mathrm{FN}_{\mathrm{CR}}\right)$

- In the case of AWS 309L inserts, the weld metal compositions at each welding speed, if superimposed on the WRC-1992 diagram [30], result in the range of F solidification mode, with higher residual ferrite content.

- The simulation with inserts made of AWS 308L shows compositions near the boundary between the FA and F mode, according to the WRC-1992 diagram. In this respect, the lowest welding speeds considered $(\mathrm{v}=0.6$ and $0.9 \mathrm{~m} / \mathrm{min})$ allows to obtain a good value of residual ferrite and an FA solidification mode.

- In the case of autogenous welding, the WRC-1992 diagram shows for the AISI 304 composition an FA solidification mode and a residual ferrite content $\mathrm{FN}=7$, which is suitable to enhance the resistance to solidification cracking, avoiding at the same time any negative effect due to an excessive content.

- The residual ferrite contents obtained by the mathematical modeling of its relationship with FZ composition [32], even if are slightly underestimated in comparison to those reported on the WRC-1992 diagram, confirm the criticality of using AWS 309L inserts in terms of an excessive residual ferrite content.

- Near the welding axis the maximum cooling rate is not significantly affected by changes of the welding speed. However, it is reduced moving towards the boundary of the fused zone, becoming markedly affected by the welding speed values.

- The results of analytical simulation highlight the decisive contribution of welding speed on cooling rate at the boundary of the fused zone with base metal, and consequently in the estimation of the residual ferrite content.

- Taking into account the effect of welding speed, for the simulations with the AWS 309 L inserts, the residual ferrite content result lower than those calcu- 
lated both through the WRC-1992 diagram and the FN mathematical modeling, but they remain too high in each case examined. Conversely, in the case of AISI 304 autogenous welding, the ferrite percentage result higher than those calculated both through the WRC-1992 diagram and the FN mathematical modeling; moreover the welding speed of $1.2 \mathrm{~m} / \mathrm{min}$ represents a limit value below which the residual ferrite content show values capable to guarantee good performance of the weld.

Author Contributions Conceptualization: FG, AS; Methodology, FG, AS; Investigation: FG, AS; Resources: FG, AS; Data curation: FG, AS; Writing-original draft preparation: FG, AS; Visualization: FG, AS; Supervision: FG, AS; Funding acquisition: FG.

Funding Open access funding provided by Università degli Studi di Catania within the CRUI-CARE Agreement. This work was supported by the University of Catania within the plan "PIAno di inCEntivi per la RIcerca di Ateneo 2020/2022", action line 3 "Starting Grant", project "MESOTERMM-Modellazione degli Effetti di SOrgenti TERmiche mobili a elevata potenza sulle proprietà dei Materiali Metallici".

Data Availability The raw/processed data required to reproduce these findings cannot be shared at this time as the data also forms part of an ongoing study.

\section{Declarations}

Conflict of Interest The authors have no conflicts of interest to declare that are relevant to the content of this article.

Open Access This article is licensed under a Creative Commons Attribution 4.0 International License, which permits use, sharing, adaptation, distribution and reproduction in any medium or format, as long as you give appropriate credit to the original author(s) and the source, provide a link to the Creative Commons licence, and indicate if changes were made. The images or other third party material in this article are included in the article's Creative Commons licence, unless indicated otherwise in a credit line to the material. If material is not included in the article's Creative Commons licence and your intended use is not permitted by statutory regulation or exceeds the permitted use, you will need to obtain permission directly from the copyright holder. To view a copy of this licence, visit http://creativecommons.org/licen ses/by/4.0/.

\section{References}

1. Mohammed, G.R., Ishak, M., Aqida, S.N., Abdulhadi, H.A.: Effects of heat input on microstructure, corrosion and mechanical characteristics of welded austenitic and duplex stainless steels: a review. Metals 7, 39 (2017). https://doi.org/10.3390/met7020039

2. Hafez, K.M., Katayama, S.: Fiber laser welding of AISI 304 stainless steel plates. Q. J. Jpn. Weld. Soc. 27, 69s-73s (2009). https://doi.org/10.2207/qjjws.27.69s

3. Salminen, S., Baskutis, E., Petronis, J.: Influence of welding modes on weldability of structural steel lap joints in laser welding. Laser Appl. 29, 022419 (2010). https://doi.org/10.2351/1.49832 45

4. Jones, R., Randle, V.: Sensitisation behaviour of grain boundary engineered austenitic stainless steel. Mater. Sci. Eng. A 527, 4275-4280 (2010). https://doi.org/10.1016/j.actamat.2020.09.015 
5. Manitsas, D., Andersson, J.: Hot cracking mechanisms in welding metallurgy: a review of theoretical approaches. MATEC Web of Conf. 188, 1-8 (2018). https://doi.org/10.1051/matecconf/ 201818803018

6. ValienteBermejo, M.A.: Reagent selection in austenitic stainless steel solidification modes characterization. Weld. J. 91, 133s-139s (2012)

7. Yu, P., Thompson, K.J., McCarthy, J., Kou, S.: Microstructure evolution and solidification cracking in austenitic stainless steel welds. Weld. J. 97, 301s-314s (2018). https://doi.org/10.29391/ 2018.97.026

8. Marques, E.S.V., Silva, F.J.G., Pereira, A.B.: Comparison of finite element methods in fusion welding processes: a review. Metals 10, 75 (2020). https://doi.org/10.3390/met10010075

9. Sun, Y.L., Obasi, G., Hamelin, C.J., Vasileiou, A.N., Flint, T.F., Balakrishnan, J., Smith, M.C., Francis, J.A.: Effects of dilution on alloy content and microstructure in multi-pass steel welds. J. Mater. Process. Technol. 265, 71-86 (2019). https://doi.org/10.1016/j.jmatprotec.2018.09.037

10. Kik, T.: Heat source models in numerical simulations of laser welding. Materials 13, 2653 (2020). https://doi.org/10.3390/ma13112653

11. Nezamdost, M.R., Nekouie Esfahani, M.R., Hashemi, S.H., Mirbozorgi, S.A.: Investigation of temperature and residual stresses field of submerged arc welding by finite element method and experiments. Int. J. Adv. Manuf. Technol. 87, 615-624 (2016). https://doi.org/10.1007/ s00170-016-8509-4

12. Lankalapalli, K.N., Tu, J.F., Leong, K.H., Gartner, M.: Laser weld penetration estimation using temperature measurements. J. Manuf. Sci. E. 121, 179-188 (1999). https://doi.org/10.1115/1.2831202

13. Mackwood, A.P., Crafer, R.C.: Thermal modelling of laser welding and related processes: a literature review. Opt. Laser Technol. 37, 99-115 (2005). https://doi.org/10.1016/j.optlastec.2004.02.017

14. Franco, A., Romoli, L., Musacchio, A.: Modelling for predicting seam geometry in laser beam welding of stainless steel. Int. J. Therm. Sci. 79, 194-205 (2014). https://doi.org/10.1016/j.ijthermalsci. 2014.01.003

15. Giudice, F., Missori, S., Sili, A.: Parameterized multipoint-line analytical modeling of a mobile heat source for thermal field prediction in laser beam welding. Int. J. Adv. Manuf. Technol. 112, 13391358 (2021). https://doi.org/10.1007/s00170-020-06479-0

16. Giudice, F., Sili, A.: Weld metal microstructure prediction in laser beam welding of austenitic stainless steel. Appl. Sci. 11, 1463 (2021). https://doi.org/10.3390/app11041463

17. Han, T.-K., Park, B.-G., Kang, C.-Y.: Hardening characteristics of $\mathrm{CO} 2$ laser welds in advanced high strength steel. Met. Mater. Int. 18, 473-479 (2012). https://doi.org/10.1007/s12540-012-3014-2

18. Ghosh, A., Misra, D., Acharyya, S.K.: Experimental and numerical investigation on laser welding of 2205 duplex stainless steel. Lasers Manuf. Mater. Process. 6, 228-246 (2019). https://doi.org/10. 1007/s40516-019-00090-2

19. Vitek, J.M.; David, S.A.; Hinman, C.R.: Improved ferrite number prediction model that accounts for cooling rate effects - Part 1: Model development. Weld. J. 82, 10s-17s (2003)

20. Vitek, J.M., David, S.A., Hinman, C.R.: Improved ferrite number prediction model that accounts for cooling rate effects - Part 2: Model results. Weld. J. 82, 43s-50s (2003)

21. Zhang, Y.-X., Han, S.W., Cheon, J., Na, S.-J., Gao, X.-D.: Effect of joint gap on bead formation in laser butt welding of stainless steel. J. Mater. Process Technol. 249, 274-284 (2017). https://doi.org/ 10.1016/j.jmatprotec.2017.05.040

22. Missori, S., Sili, A.: Prediction of weld metal microstructure in laser beam weld metal clad steel. Metallurgist 62, 84-92 (2018). https://doi.org/10.1007/s11015-018-0629-7

23. Kotecki, D., Armao, F.: Stainless Steels Welding Guide. The Lincoln Electric Company, Cleveland (2003) pp. 14-16

24. Rosenthal, D.: The theory of moving sources of heat and its application to metal treatments. T. ASME 43, 849-866 (1946)

25. Mills, K.C.: Recommended Values of Thermophysical Properties for Selected Commercial Alloys, pp. 127-133. Woodhead Publishing, Cambridge (2002)

26. Rai, R., Elmer, J.W., Palmer, T.A., DebRoy, T.: Heat transfer and fluid flow during keyhole mode laser welding of tantalum, Ti-6Al-4V, 304L stainless steel and vanadium. J. Phys. D Appl. Phys. 40, 5753-5766 (2007). https://doi.org/10.1088/0022-3727/40/18/037

27. Wang, H., Nakanishi, M., Kawahito, Y.: Effects of welding speed on absorption rate in partial and full penetration welding of stainless steel with high brightness and high power laser. J. Mater. Process Technol. 249, 193-201 (2017). https://doi.org/10.1016/j.jmatprotec.2017.06.014 
28. Weman, K.: Welding Processes Handbook, 2nd edn., pp. 198-201. Woodhead Publishing, Cambridge (2012)

29. Vashishtha, H., Taiwade, R.V., Sharma, S., Patil, A.P.: Effect of welding processes on microstructural and mechanical properties of dissimilar weldments between conventional austenitic and high nitrogen austenitic stainless steels. J. Manuf. Process. 25, 49-59 (2017). https://doi.org/10.1016/j. jmapro.2016.10.008

30. Kotecki, D.J., Siewert, A.: WRC-1992 Constitution diagram for stainless steel weld metals: a modification of the WRC-1988 diagram. Weld. J. 71, 171s-178s (1992)

31. Bunaziv, I., Olden, V., Akselsen, O.M.: Metallurgical aspects in the welding of clad pipelines: a global outlook. Appl. Sci. 9, 3118 (2019). https://doi.org/10.3390/app9153118

32. Valiente Bermejo, M.A.: A mathematical model to predict $\delta$-ferrite content in austenitic stainless steel weld metals. Weld. World 56, 48-68 (2012). https://doi.org/10.1007/BF03321381

33. Alvarez-Armas, I., Degallaix-Moreuil, S.: Duplex Stainless Steels, pp. 142-143. Wiley, Hoboken, NJ (2009)

34. Elmer, J.W., Elmer, S.M., Eagar, T.W.: Microstructural development during solidification of stainless steel alloys. Metall. Trans. A 20, 2117-2131 (1989). https://doi.org/10.1007/BF02650298

35. Valiente Bermejo, M.A., DebRoy, T., Hurtig, K., Karlsson, L., Svensson, L.-E.: Towards a map of solidification cracking risk in laser welding of austenitic stainless steels. Phys. Proc. 78, 230-239 (2015). https://doi.org/10.1016/j.phpro.2015.11.033

Publisher's Note Springer Nature remains neutral with regard to jurisdictional claims in published maps and institutional affiliations.

\section{Authors and Affiliations}

\section{Fabio Giudice $^{1}$ (D) Andrea Sili ${ }^{2}$ (D)}

Andrea Sili

asili@unime.it

1 Department of Civil Engineering and Architecture, University of Catania, Via Santa Sofia 64, 95123 Catania, Italy

2 Department of Engineering, University of Messina, Contrada di Dio, 98166 Messina, Italy 